\title{
Correction to: Mathematics and Computation in Music
}

\author{
Mariana Montiel (D), Francisco Gomez-Martin (D), \\ and Octavio A. Agustín-Aquino (iD
}

\section{Correction to: \\ M. Montiel et al. (Eds.): Mathematics and Computation in Music, LNAI 11502, https://doi.org/10.1007/978-3-030-21392-3}

Maria Mannone was not given credit for the cover logo in the original version. This was corrected.

The original version of chapter 14, "Distant Neighbors and Interscalar Contiguities" was revised. This chapter was previously published non-open access. It was changed to open access retrospectively under a CC BY 4.0 license. The book has also been updated with the change.

The updated version of the book can be found at 